\title{
Moving Beyond Time Value of Money: The Application of Macroeconomic Theory to Capital Investment Decision-Making
}

\author{
Peter M. Boerger \\ Purdue University
}

\section{Introduction}

Considering that the two fields share the same word root, an outsider to the field of engineering economy might assume that the fields of macroeconomics and engineering economy are closely related and have experienced significant cross-fertilization. In fact, as those who practice in the field of engineering economy will attest, this assumption would be far from the truth.

Engineering economy texts are written with little or no mention of macroeconomic theory. Most books introduce engineering economy through linking it to the notion of a "decision" and then launch right into time value of money methods. There is nothing wrong with this approach if in fact macroeconomics has nothing to offer in furthering the work of engineering economy, however that assumption is wrong.

This paper will show that there is theory from macroeconomics which is relevant to the engineering economic problem. As such, engineering economists can improve their investment choices if they incorporate that theory into their decision models. The justification of this statement and an approach to applying it are the substance of this paper.

The notion of applying macroeconomic principles to engineering economy is not totally new. Horowitz, in response to a request to review the status of engineering economy in 1976 called for engineering economists to apply recent economic developments to their task. ${ }^{3}$ This paper can be seen as expanding on Horowitz's call.

\section{Why the Divide?}

Why is it that engineering economy and macroeconomics are so separated? Part of the reason is the difference in their objectives. Engineering economy seeks to help firms improve their capital investment decisions. Macroeconomics in contrast has a broader goal; it is concerned with understanding how resources are allocated in an economy. From appearances, these look like quite disparate objectives and so the lack of communication between the fields seems understandable.

However, upon closer examination we see that these fields are closer than they first appear. Macroeconomics accomplishes its goal in part through developing an understanding of how firms make decisions. This looks closer to the engineering economic objective which provides decision-making models. It might be said that this similarity is illusory in that the engineering economic approach to decision-making is "normative," telling firms how they should behave, while macroeconomics is "positive," concerned with how rational firms do behave. However, the way firms should behave is exactly how rational firms do behave, so the two fields do not 
differ at all in this respect. Thus, it would seem that macroeconomic models of how rational firms behave should be relevant to the engineering economic problem.

There is however still a difference between the fields evidenced by the above definitions. Engineering economy is concerned with capital investment decisions, whereas macroeconomics is not restricted so. In fact, this is a crucial distinction. Macroeconomics does not even recognize the conception of the "multiple mutually exclusive alternatives" decision problem. To a macroeconomist, a decision is either "go" or "no go. "If the product (which might imply an investment) yields an "economic profit" (IRR > MARR), then the product will be produced, else it will not. If there are three alternatives which all yield an economic profit, then all three will be produced in the macroeconomic world. Above-MARR returns, commonplace to the engineering economist, are viewed as quite unusual and hence worthy of investment to the macroeconomist, trained to focus on the "perfectly competitive equilibrium. " Engineering economists in contrast might be thought of as working in Schumpeter's world of disequilibrium, where the market always affords opportunities for above-market returns to the opportunistic investors This difference is clearly another reason for the lack of interaction between the fields of macroeconomics and engineering economy.

\section{Bridging the Gap Between the Fields}

So does macroeconomics' lack of attention to investment alternatives lead to the conclusion that microeconomic theory provides no help for the investment decision problem of engineering economy? In fact no, but the applicability is a bit subtle.

To get at the connection, consider the decision variables in each field. In engineering economy the choice is between alternative investments, and so the decision variable might be called "alternative." In microeconomics there is only one possible alternative (besides "do nothing"), but there is another decision variable typically used in that field of study: quantity. The firm is thought to choose quantity so as to maximize profit.

Consider now the nature of these two decision variables. The quantity of the good that a firm produces is selected in the short run in accordance with the environment in which the firm operates: its input and output markets. Depending on how the firm's production costs vary with output and the way that the product market values marginal quantities, the firm will produce greater or lesser volumes.

In contrast, the investment alternative is selected before these market conditions are even realized. An investment might be committed a year or more before the firm enters the market with a product. So how does the engineering economic decision variable "alternative" relate to the macroeconomist's decision variable "quantity"?

The answer lies in recognizing that the engineering economist's decision affects the firm's later decisions, which will be made over rnicroeconomic decision variables. As stated above, the firm's optimal choice of quantity will be affected by the way that production costs vary with output. Well, what other than the production system affects these costs and hence the firm's choice of quantity. It is the choice of investment alternative which can affect the production system, its costs, and hence the firm's optimal choice of quantity.

We have one last step to provide the bridge that we seek. Whale we have shown that the engineering economic decision can affect the firm's rnicroeconomic choices, the point of this paper is to show how microeconomic theory can affect engineering economic decisions. To make this final connection we must only realize that the firm's expectations for the market that it will face in the future should in some way affect the type of 
production system that it puts in place now. If the market is expected to "want" (in some sense) large quantities, then this fact should be communicated to the investment decision analysis, giving an edge to alternatives which are "better" (in some sense) at producing in high volumes.

We have talked about the quantity decision variable here. There is another macroeconomic decision variable which is less commonly seen in the macroeconomic literature but which is of great importance to the engineer: product "quality." The word quality has an economic definition here--meaning that the product has a higher usefulness to the purchaser, not to be confused with the engineering or other meanings for quality. See Garvin for a discussion of different definitions for the word "quality" and Boerger for a further justification of the one used here. ${ }^{2,1}$ The rational firm will consider not only its choice of quantity but also its choice of quality so as to maximize profit, and the rational investor will include consideration of how the market values quality as part of the decision analysis. For simplicity, detailed explanations below will focus on only the quantity variable.

\section{Formalizing the Conceptual Bridge}

We saw above in a conceptual way how macroeconomic theory might be relevant to helping the firm make better investment decisions. That theory has no value however unless we can implement it into actual engineering economic analyses. The implementation suggested below not only provides for better investment decisions, it puts the investment selection process itself in an entirely new analytical light.

The technique that will be used to formalize the conceptual bridging from above is that of a "mapping." A mapping transforms one set of variables to another, presumably because a desired analysis is performed more easily over one variable than another. As shown in Figure 1 the mapping needed is from a set of "alternatives" to a set of cost functions.

A cost function is itself a mapping from a domain (quantity or quality) to a range (total or average cost), but the mapping here is not so straightforward. What makes it difficult is that the "alternative" variable is not only discrete, it cannot even be ordered over some scale in a consistent way, as for instance quantity can. We know that the quantity labeled " 200 " is twice as great as the quantity labeled " 100 ," but an investment alternative labeled " 2 " is not two times as much of anything compared to the alternative labeled " 1 . " This is because the alternatives " 1 " and " 2 " might just as easily be labeled " 2 " and " 1 " or "A" and "B." Labels on the "alternative" decision variable are hence not able to be ordered in any meaningful way based on their labels alone.

This situation does not present a problem in the standard engineering economic approach because there is no optimization method used for obtaining the optimal investment choice. The engineering economic method says merely "evaluate present worth for all feasible alternatives and choose the one with the highest value." The ordering of the alternatives occurs only over the present worth variable with no dependence at all on an ordering over the decision variable "alternative."
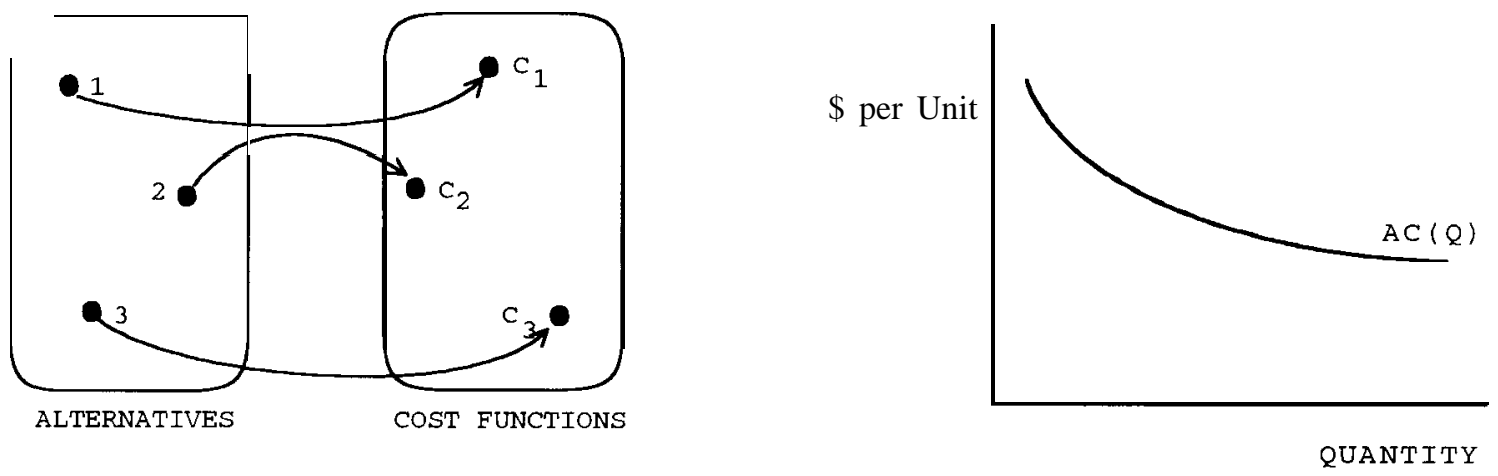

Figure 1 Mapping from Alternatives to Cost Functions

Figure 2 Image of an Investment Alternative 1996 ASEE Annual Conference Proceedings 
However, the application of macroeconomic models does require consistent ordering over decision variables. Unlike with engineering economic problems with limited number of feasible "alternatives," the decision variable "quantity" is continuous, implying an infinite number of possible solutions. Hence, macroeconomic theory makes use of efficient optimization procedures (such as Lagrange optimization) which require consistent ordering of possible decision variable values.

This understanding is important because it tells us that if macroeconomic theory is to be applied to the investment decision problem, it must be done in macroeconomic space rather than engineering economic space. What this requires is that investment alternatives be mapped over the quantity decision variable rather than the other way around.

Figure 2 shows the image of an investment alternative over a quantity decision variable. For discussion of the reasoning behind the shape of this function see Boerger (1 995). '

The investment alternative is mapped in this figure to an average cost function. Though it could be mapped to a total cost function (in that "first cost s" are represented in both), average cost functions are chosen to coincide with the per-unit decision space normally illustrated in macroeconomic analyses.

The average cost function of macroeconomics does not include the time value of money, a significant disadvantage for investment analysis. To overcome this problem, we assume that the uniform annual equivalent of the first cost is divided by the number of units expected per year to arrive at an equivalent uniform annual average cost (EUAAC, see Boerger).' In this way the optimization performed in macroeconomic space can be legitimately used to solve problems in which the time value of money is a significant factor. See Appendix 1 for a justification of this approach.

\section{Optimal Choice of Investments in a Monopolistic Market}

Having shown how the engineering economist's investment alternatives can be mapped into microeconomic space, it remains to be shown how macroeconomic theory can be used to improve the firm's investment choice. The treatment in this section will be a synopsis of that found in Boerger (1995).1 If quantity is expected to be the only decision variable available to the firm after the production investment is made, then the firm may face a decision environment such as that shown in Figure 3 (for a discussion of the monopolist's

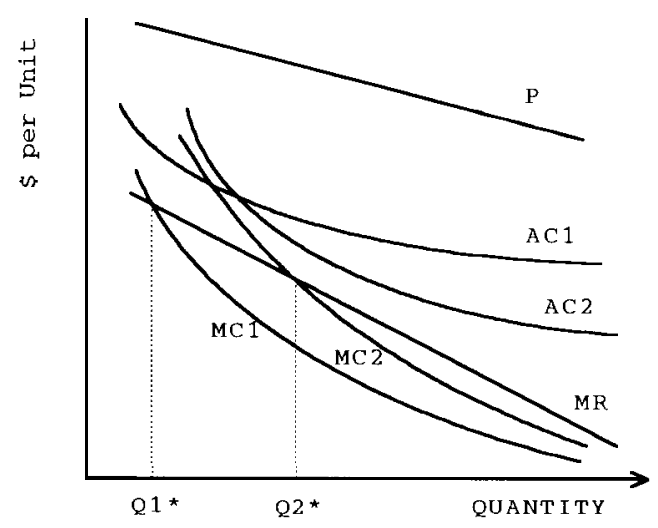

Figure 3 Selection of Optimal Quantity for Two Alternatives 
problem and other macroeconomic theory, see e.g. Varian). "Quantity" here means "quantity per unit of time" or more commonly known as "production capacity."

Note that there are two investment alternatives available to this firm (besides "do nothing"). The nonprice-discriminating monopolist (can only charge one price in the market) seeks to restrict output so as to raise the price for its product to the point where profit is maximized. Macroeconomic theory tells us that this will occur at the point where the marginal revenue (first derivative of revenue with respect to output) from additional output just equals the marginal cost (first derivative of cost with respect to output).

The optimal investment choice is the one which minimizes EUAAC at the profit maximizing output level. This is so because once the optimal output level is chosen, it would be irrational to choose any input which costs more than the minimum. If the two alternatives evidence different marginal cost characteristics over quantity, then they will result in two different optimal quantity levels. The investment alternative with the minimum EUAAC at each optimal quantity is the one which should be used at each potentially optimal quantity level. If there is more than one potentially optimal investment alternative, then profit for each should be calculated and the one yielding the highest value should be chosen. Since "profit" is calculated using EUAAC, what is actually being maximized is present worth, and the choice is optimal considering the time value of money.

Thus we can see that recognizing the environment in which the firm operates and incorporating that into the investment decision can lead to better investment decisions than if that information were not incorporated. While one might argue that these monopolistic influences could be included in the standard engineering economic approach through the specification of revenues from marketing professionals who are familiar with the market, this in fact cannot be done optimally. Marketing professionals cannot specify the optimal output for the firm without consideration of the firm's marginal cost function, information which is clearly in the domain of the engineering economist. Thus the incorporation of the monopolistic nature of the firm's environment is not as simple as it might first appear, and the method presented here gives an approach that will lead to an optimal solution.

\section{Other Potential Applications of Macroeconomic Theory}

The preceding analysis gives one example of a market situation that might affect the investment choice of a firm. There are other market types which can be equally relevant. For instance, in an oligopolistic market there is relatively less interest in the firm-customer relationship and more in firm-firm relationships (see e.g. Krouse for a complete description of this type of market). ${ }^{4}$ In such a market, firms are free to respond to actions taken by other firms in the market.

If one firm increases its production output, another firm might either lower its production so as to maintain the market price or it might raise its own production to lower the market price, thus sanctioning the other firm's increase. As with the monopoly market, the result of the investor's analysis in this type of market will result in a quantity level that is expected to maximize present worth, and thus investment selection will be affected in the same way for this market as in the monopolistic market. However, now the ability of the investment alternative to reduce the firm's strategic risk and the level of risk averseness of the investor will also need to be included in the decision analysis. How this is done is left to further research.

The example in the previous section used only quantity as a macroeconomic decision variable. If quality were also included, the problem would become much more complex and interesting. Also adding interest and 
difficulty to the problem would be the ability of the firm to produce more than one product in the market with its investment.

While the engineering economist is only concerned with achieving above-market returns as stated earlier, the knowledge of a perfectly competitive equilibrium might also be useful to his or her investment analysis. While a monopoly market might indicate one product quantity or quality to maximize present worth under that regime, economic theory says that over time competitors will enter the market and eliminate above market returns. While Schumpeter posits that this equilibrium maybe usurped before it is ever reached, there is no doubt that there are market forces which will motivate competitive actions in that direction and the investor, having a sunk stake in the market, may want to know up front how competitive or uncompetitive each investment alternative looks at equilibrium quantity and quality levels. ${ }^{5}$ In addition, economic theory regarding the dynamics of these changes can help the investor to set the time horizon for the investment analysis. For instance, if competitors are expected to enter early, then the time horizon for the investment analysis should be relatively short.

These examples are only the obvious avenues for thinking about how economic theory might be usefully applied to making better investment decisions. A comprehensive review of topical areas in economic theory would likely uncover many more applications. But considering only these, there appears to be much potential for this avenue of improving investment decision-making.

\section{Conclusions}

This paper has shown that economic theory can be used to improve the firm's selection among production investment alternatives. The reason that such improvement occurs is because economic theory models characteristics of firm behavior in response to its environment which is not currently included in engineering economic theory. This behavior occurs once the firm's production investment is already in place, so it makes sense that if the firm's investment can position the firm to act in a more profitable way, then such an implication should be considered before the investment is made.

Such consideration was shown here to be possible through the mapping of investment alternatives onto macroeconomic decision variables. Only by placing the alternatives in the context of the firm's later decision variables can economic insights over those variables be applied to the investment decision problem. It is hoped that this paper serves as an initial step to looking beyond engineering economy's standard and important methods--involving mainly the discounting of cash flows--to techniques which might help make firms more competitive in the 21 st century.

\section{Acknowledgments}

The author would like to acknowledge the helpful input provided by Dr. F.T. Sparrow over the course of this research.

\section{Appendix 1}

We want to show that EUAAC identifies the optimal investment choice once the optimal quantity is chosen for a non-price-discriminating monopolist. To begin, we note that once the optimal quantity per unit of time is chosen (the production capacity), that the revenue from the investment is fixed (since the price is fixed by the quantity). Hence, if there is more than one investment alternative which can produce at the selected output level, the optimal selection is clearly the one which minimizes EUAC, as is proven in elementary engineering economy textbooks. But we know that EUAC is simply EUAAC multiplied by the chosen quantity. Minimizing EUAAC is precisely the same as minimizing EUAC/Quantity. Since minimizing EUAC divided by some fixed 
quantity will lead to the same investment selection as minimizing over EUAC alone, and thus minimizing EUAC at a fixed quantity will necessarily lead to selection of the optimal investment alternative at that quantity.

\section{References}

[1] Boerger, Peter M. "Engineering Economy in a Framework of Concurrent Engineering:

Linking Revenue Generation to the Investment Decision Problem. "Working Paper. West Lafayette, 1N: Institute for Interdisciplinary Engineering Studies, 1995.

[2] Garvin, D.A. “What Does 'Product Quality’ Really Mean?” Sloan Management Review 26.1 (1984): 25-43.

[3] Horowitz, I. "Engineering Economy: An Economist's Perspective. " AIIE Transactions 8 (1976): 430-42.

[4] Krouse, Clement G. Theory of Industrial Economics. Cambridge, MA: Basil Blackwell, 1990.

[5] Schumpeter, J. Capitalism, Socialism and Democracy. 5th Edition. London: Allen and Unwin, 1976.

[6] Varian, Hal R. Intermediate Microeconomics: A Modern Approach. 2nd Edition. New York: Norton, 1990 .

\section{Biographical Information}

Peter Boerger is completing his Ph.D. in Industrial Engineering at Purdue University. He has worked in a manufacturing environment as a development engineer and has researched and published numerous reports in areas of technology \& public policy and economic development while employed in state government-related organizations. He has taught undergraduate engineering economy at Purdue a number of semesters and is a registered professional engineer. 